\title{
Evolution of colicin BM plasmids: the loss of the colicin $B$ activity gene
}

\author{
Correspondence \\ David M. Gordon \\ David.Gordon@anu.edu.au
}

Received 11 December 2008

Revised 29 January 2009

Accepted 3 February 2009

\author{
Julia K. Christenson and David M. Gordon \\ School of Biology, Australian National University, Canberra, ACT 0200, Australia
}

\begin{abstract}
Colicins, a class of antimicrobial compounds produced by bacteria, are thought to be important mediators of intra- and interspecific interactions, and are a significant factor in maintaining microbial diversity. Colicins $\mathrm{B}$ and $\mathrm{M}$ are among the most common colicins produced by Escherichia coli, and are usually encoded adjacently on the same plasmid. In this study, the characterization of a collection of $E$. coli isolated from Australian vertebrates revealed that a significant fraction of colicin BM strains lack an intact colicin B activity gene. The colicin B and M gene region was sequenced in 60 strains and it was found (with one exception) that all plasmids lacking an intact colicin $\mathrm{B}$ activity gene have an identical colicin gene structure, possessing a complete colicin $B$ immunity gene and a 130 bp remnant of the $B$ activity gene. A phylogenetic analysis of the colicin $\mathrm{M}$ and $\mathrm{B}$ operons and characterization of the plasmids suggested that ColBM plasmids with a truncated B activity gene have evolved on at least three separate occasions. Colicin B immunity was found to be non-functional in strains that have lost colicin B activity, and colicin M was still produced despite the absence of the SOS box believed to regulate its production in colicin BM strains. The presence of a remnant of the microcin $\mathrm{V}$ operon next to the truncated colicin $B$ activity gene indicated that these plasmids evolved as a consequence of gene transfer between colicin BM and microcin V plasmids. We suggest that these transfer events most likely involved the transfer of some microcin $\mathrm{V}$ genes and associated virulence factors onto ColBM plasmids.
\end{abstract}

\section{INTRODUCTION}

Bacteriocins are a diverse group of antimicrobial toxins that are produced by all species of bacteria (Riley \& Wertz, 2002; Riley et al., 2003). Unlike traditional broad-spectrum antibiotics, bacteriocins have a narrow killing range and are generally only toxic to susceptible strains of the same or a closely related species (Riley \& Wertz, 2002). Evidence suggests that bacteriocins are important mediators of intraand interspecific interactions and thus play a significant role in maintaining microbial biodiversity (Czaran et al., 2002; Kirkup \& Riley, 2004). Understanding the evolution and ecology of bacteriocins has become particularly important due to their potential as a replacement for traditional antibiotics in the treatment of bacterial infections and because they are considered to be a key trait of probiotic bacteria (Gillor et al., 2004, 2008a). Escherichia coli is known to produce two classes of bacteriocins: microcins and colicins. The colicins are highly diverse and widespread in natural E. coli populations. This study

The GenBank/EMBL/DDBJ accession numbers for the colicin B and M gene region sequences of the Escherichia coli strains analysed in this study are FJ664714-FJ664773.

A supplementary table, listing primers used for colicin $B$ and $M$ gene sequencing, is available with the online version of this paper. concerns two colicins commonly found to co-occur in $E$. coli strains: colicin B and colicin M.

Recent studies have revealed that a high proportion of bacteriocinogenic E. coli strains produce more than one type of bacteriocin (Gordon \& O’Brien, 2006; Gordon et al., 2007). Multiple bacteriocin production can confer a number of advantages, the most obvious being an expanded killing range (Czaran et al., 2002). Consider a bacterial community consisting of two different singlecolicin-producing populations: a cell that acquires the genes necessary to produce both colicins will have a competitive advantage. The multiple producers will be able to kill sensitive cells as well as cells that produce only a single colicin type. Other proposed advantages of multiple bacteriocin production are an expanded receptor repertoire and an enhanced fitness in a wider range of habitats if the bacteriocins are induced under different conditions (Gordon \& O’Brien, 2006).

Colicins $\mathrm{B}$ and $\mathrm{M}$ have been found to co-occur at a significantly greater frequency than expected by chance (Gordon et al., 2007). The colicin B and M gene operons are almost always found in close proximity on the same large conjugative plasmid (Ölschläger et al., 1984; Sasarman et al., 1980). Each operon consists of two tightly 
linked genes: an activity gene, which encodes the killing protein; and a constitutively expressed immunity gene, which encodes an immunity protein that protects the cell from its own colicin (Riley \& Gordon, 1999). The colicin B and $\mathrm{M}$ activity genes are transcribed in the same direction, while the immunity genes are transcribed in the opposite direction (Ölschläger et al., 1984). Unlike most colicins, colicins $\mathrm{B}$ and $\mathrm{M}$ have no associated lysis proteins, and are actively secreted from the cell by unknown mechanisms (Harkness \& Ölschläger, 1991; Ölschläger et al., 1984). The expression of most colicins is induced under conditions of stress via the SOS response (Lu \& Chak, 1996), and studies indicate that expression of both colicin B and colicin $M$ is regulated at the same SOS box located upstream of the B activity gene (Gillor et al., 2008b; Köck et al., 1987; Ölschläger et al., 1984). Colicin B has a molecular mass of $54.7 \mathrm{kDa}$ (Schramm et al., 1987), while colicin M is the smallest known colicin, with a molecular mass of $29.5 \mathrm{kDa}$ (Köck et al., 1987). The receptors exploited by colicins B and $\mathrm{M}$ to enter a sensitive cell are the siderophore receptors FepA and FhuA, respectively. Upon recognition, colicins B and $\mathrm{M}$ are imported into the cell by the Ton system (Braun, 1995; Braun et al., 2002). Colicin B is a member of the pore-forming colicins, and kills sensitive cells by forming ion channels that depolarize the cytoplasmic membrane, leading to dissipation of cellular energy (Pressler et al., 1986). Colicin $\mathrm{M}$ is unique in its killing action, causing lysis of target cells by inhibiting biosynthesis of peptidoglycan and lipopolysaccharide O-antigen (Braun et al., 1974; Harkness \& Braun, 1989a, b; Schaller et al., 1982).

Colicins $\mathrm{B}$ and $\mathrm{M}$ are among the most common colicins in E. coli, and they normally co-occur in the same strain. In a collection of $E$. coli isolated from Australian vertebrates, PCR screening of the strains positive for colicin $\mathrm{M}$ but not colicin $\mathrm{B}$ revealed that $90 \%$ of these strains also possessed the colicin B immunity gene. This suggested that these strains have evolved from colicin BM strains that have lost their colicin B activity gene. Because of the known fitness advantages associated with multiple colicin production, the widespread loss of the colicin B activity gene is surprising. The purpose of this study was to characterize ColBM plasmids with a truncated colicin $B$ activity gene.

\section{METHODS}

Strain collections. The strains used in this study were from two existing E. coli collections. The first collection consists of 685 isolates from Australian reptiles, birds and mammals (Gordon \& Cowling, 2003), and the second consists of 619 clinical and faecal isolates taken from humans living in Australia (Gordon et al., 2005). All isolates had been previously assayed for a mitomycin C-inducible colicin phenotype, as described by Gordon et al. (1998), and PCR-screened for 11 colicins (B, M, Ia, Ib, E1, E2, E6, E7, K, A, D) and seven microcins (M, L, V, C7, H47, B17, J25) (Gordon et al., 2007). Strains had also been assigned to one of four E. coli phylogroups, A, B1, B2 and D (as per Clermont et al., 2000).
PCR screening. The colicin BM genotype of each strain $[B, M, M$ with $\mathrm{B}$ immunity gene (MBimm) or BM] was determined using colicin $\mathrm{B}$ and $\mathrm{M}$ screening primers from a previous study (Gordon \& O'Brien, 2006) as well as a primer in the colicin B immunity gene (2083-R: 5'-CCCCAGAAACAGGATTGCAC-3'). All colicin B/M strains were also PCR-screened for nine plasmid-borne genes $(t s h$, iroN, traT, sitA, $h l y F$, eitA, iutA, iss and etsA) with primer sequences and annealing temperatures obtained from earlier studies (Johnson et al., 2006a, b; Rodriguez-Siek et al., 2005). Template DNA was extracted from bacterial cells by treating $50 \mu$ of overnight Luria broth cultures (incubated at $37{ }^{\circ} \mathrm{C}, 150$ r.p.m.) with DNAzol (Invitrogen) according to the manufacturer's protocol. Single and multiplex PCR assays were performed in a $20 \mu \mathrm{l}$ reaction mixture consisting of $1.2 \mu \mathrm{l}$ template DNA, $0.2 \mu$ Platinum Taq polymerase, $0.8 \mu \mathrm{l}$ of each primer $(10 \mu \mathrm{M})$ and $4 \mu \mathrm{MgCl}_{2}(25 \mathrm{mM})$ in $1 \times \mathrm{PCR}$ buffer [67 mM Tris/ $\mathrm{HCl}(\mathrm{pH} 8.8), 16.6 \mathrm{mM}\left(\mathrm{NH}_{4}\right)_{2} \mathrm{SO}_{4}, 0.45 \%$ Triton X-100, $0.2 \mathrm{mg}$ gelatine $\mathrm{ml}^{-1}$ and $0.2 \mathrm{mM}$ dNTPs]. Basic PCR conditions were as follows: one cycle of $95{ }^{\circ} \mathrm{C}$ for $12 \mathrm{~min}$; 25 cycles of $94{ }^{\circ} \mathrm{C}$ for $30 \mathrm{~s}, 55{ }^{\circ} \mathrm{C}$ for $30 \mathrm{~s}, 68^{\circ} \mathrm{C}$ for $3 \mathrm{~min}$; and one cycle of $72{ }^{\circ} \mathrm{C}$ for $10 \mathrm{~min}$. Amplified DNA fragments were run alongside a $100 \mathrm{bp}$ ladder on $2 \%$ agarose gels containing ethidium bromide and visualized under UV light.

Sequencing. The entire colicin $\mathrm{B}$ and $\mathrm{M}$ gene region was sequenced for $60 \mathrm{E}$. coli strains selected to represent the diversity present among the strains encoding these genes. Primers for sequencing were designed as needed using published colicin $\mathrm{B}$ and $\mathrm{M}$ gene sequences (Johnson et al., 2006a; Köck et al., 1987; Ölschläger \& Braun, 1987; Schramm et al., 1987, 1988) (Supplementary Table S1). DNA fragments were amplified using the PCR conditions described above, and PCR products were purified with the DNA purification reagent ExoSAP-IT (USB). Sequencing reactions were set up with 10-20 $\mu \mathrm{g}$ purified PCR product using BigDye terminator chemistry according to ABI standard protocols (Applied Biosystems). DNA nucleotide sequences were read with an ABI Prism 3100 Genetic Analyzer and subsequently edited and aligned using Sequencher (Gene Codes). Sequence data obtained in this study have been submitted to the GenBank database under accession numbers FJ664714-FJ664773.

Phylogenetic analyses and sequence diversity. Maximumlikelihood trees were constructed in PAUP ${ }^{*} 4.0 \mathrm{~b} 10$ (Swofford, 1993) using evolutionary model parameters obtained from MODELTEST 3.06 (Posada \& Crandall, 1998). Tree topology confidences were assessed by performing bootstrap analyses using 1000 replicates. MEGA4 (Tamura et al., 2007) was used to perform tests for selection and to calculate sequence diversity.

Obtaining transconjugants. Mating experiments were performed to transfer colicin plasmids into the recipient laboratory strain BZB1011, a nalidixic acid-resistant derivative of E. coli K-12 W3110 (Pugsley, 1985). The methods used were a variation of those described by Pugsley \& Oudega (1987). Antibiotic selection was used to isolate potential transconjugants. Initially all colicin B- or M-positive E. coli were screened for resistance to eight antibiotics whose resistance genes are often plasmid-encoded: ampicillin, streptomycin, tetracycline, chloramphenicol, nalidixic acid, kanamycin, trimethoprim and sulfamethoxazole trimethoprim, using BBL Sensi-Disc antimicrobial susceptibility test discs (BD) according to the manufacturer's protocol. Transconjugants were then selected using nalidixic acid together with $0.0025 \mathrm{mg}$ tetracycline $\mathrm{ml}^{-1}, 0.02 \mathrm{mg}$ ampicillin $\mathrm{ml}^{-1}$ or $0.5 \mathrm{mg}$ trimethoprim $\mathrm{ml}^{-1}$. Putative transconjugants were stored as $10 \%(\mathrm{v} / \mathrm{v})$ glycerol cultures at $-80{ }^{\circ} \mathrm{C}$.

Colicin plasmid characterization. Template DNA was extracted from putative transconjugant strains, and PCR-based screening was undertaken to confirm that they were true colicin plasmid transconjugants. Strains were confirmed as transconjugants if they 
were positive for the colicin $\mathrm{M}$ gene and negative for a chromosomally encoded gene present in the wild-type strain but not in BZB1011 [either chuA or the DNA fragment TSPE4.C2 (Clermont et al., 2000)]. Confirmed transconjugants were characterized by screening for the nine plasmid genes tsh, iroN, traT, sit $A, h l y F$, eit $A$, iut $A$, iss and etsA, and for any bacteriocins present in the wild-type strain. They were also characterized for a number of factors associated with plasmid conjugation. Primer sequences from earlier studies were used to screen for finO (Boyd et al., 1996) and IncFII (Osborn et al., 2000), and to determine whether their traY gene was characteristic of an F- or R1-type plasmid (Boyd et al., 1996).

A modified in-well lysis technique was used to roughly estimate the size of the colicin B and M plasmids on electrophoresis gels (de Souza et al., 1998). Colicin B- and M-carrying plasmids were identified by comparing the plasmid content of wild-type and transconjugant strains. Electrophoresis gels were prepared in TBE buffer $(44.5 \mathrm{mM}$ Tris-borate, $1.3 \mathrm{mM}$ EDTA, $\mathrm{pH} 8.0$ ) with $0.75 \%(\mathrm{w} / \mathrm{v})$ agarose and $1 \%(\mathrm{w} / \mathrm{v})$ SDS. Overnight cell culture was added directly to wells preloaded with lysis solution $\left[1.0 \mathrm{mg}\right.$ lysozyme $\mathrm{ml}^{-1}, \quad 15.5 \mu \mathrm{g}$ RNase $\mathrm{ml}^{-1}$ and $20 \%(\mathrm{w} / \mathrm{v})$ sucrose in TBE]. Strains of interest were run alongside five reference strains carrying a single plasmid of known size (R388, $32 \mathrm{~kb}$; R136, $62 \mathrm{~kb}$; R1, $92 \mathrm{~kb}$; pIP40a, $145 \mathrm{~kb}$; MIP233, $227 \mathrm{~kb})$. Migration distances of DNA bands were measured directly from photographs of the gels. Colicin BM plasmids are known to be large (50-200 kb) (Johnson et al., 2006a), so when only one large plasmid was present in a wild-type strain it was assumed to be the colicin BM plasmid.

Colicin BM killing assay. All transconjugant strains obtained in this study were assayed for susceptibility to three colicin BM extracts prepared using the method described by Gordon et al. (1998). Each colicin BM extract was tested on ColBM and ColMBimm transconjugant strains (using the colicin-sensitive BZB1011 as a control). Strains were scored as being susceptible to the extract if there was an area of growth inhibition where the colicin BM extract was deposited.

Killing phenotype in colicin MBimm strains. Colicin M cannot be induced by the DNA mutagen mitomycin C (Braun et al., 1974), so an alternative method for determining whether colicin $\mathrm{M}$ is produced in colicin MBimm strains was required. It was noted that BZB1011 has partial resistance to low concentrations of the bacteriostatic antibiotic tetracycline. A zone of inhibition was observed around colonies of tetracycline-resistant colicinogenic strains when grown with a lawn of BZB1011 on a Luria agar plate containing tetracycline. An overnight culture of the colicin-sensitive laboratory strain BZB1011 was spread over Luria agar plates containing $1 \mu \mathrm{g}$ tetracycline $\mathrm{ml}^{-1}$. Colicin BM and MBimm strains resistant to tetracycline were cultured and serially diluted, and a small aliquot was spread over the same plate. A visible zone of inhibition around the colicin MBimm colonies was taken to indicate colicin production in these strains.

\section{RESULTS}

\section{Distribution of colicins $B$ and $M$ in $E$. coli}

Colicin B and/or M genes were detected in 128 of the 1304 E. coli strains examined in this study. Of these 128 strains, $69 \%$ were positive for both colicins, $3 \%$ were positive for only colicin $\mathrm{M}$, and $28 \%$ were positive for colicin $\mathrm{M}$ and the colicin B immunity gene. None of the strains was positive for colicin B alone. Strains encoding the colicin M genes and the colicin B immunity gene (but no colicin B activity gene) are referred to as colicin MBimm strains. E. coli was isolated from two main host groups: humans and animals (non-human mammals, birds and reptiles). All isolates had been previously assigned to one of four main phylogenetic groups of E. coli (A, B1, B2 and D) using the method of Clermont et al. (2000). An analysis was undertaken to determine the extent to which host group and E. coli phylogroup membership could be used to predict the colicin genotype of a strain. The colicin genotypes distinguished in the analysis were (1) BM, (2) MBimm and (3) neither BM nor MBimm. Strains with colicin M but no colicin B immunity gene were excluded from this analysis due to their rarity. Host group (human versus non-human animal) was found to have a significant effect on the probability of detecting a particular colicin genotype, but the probability of detecting a particular colicin genotype was independent of the phylogenetic group membership of a strain (nominal logistic regression: host group $\chi_{(2)}^{2}=59.36, P=0.000 ; E$. coli phylogroup $\chi_{(6)}^{2}=11.45, \quad P=0.076 ; \quad E$. coli phylogroup $\times$ host group $\chi_{(6)}^{2}=10.99, P=0.089$ ). As previously reported (Gordon $e t$ al., 2007), strains isolated from non-human animals were significantly more likely to be BM-positive than strains isolated from humans (Table 1). The reason for this is unknown, and this host-group effect has not been observed among other colicins. However, host group had no effect on the probability of detecting a colicin MBimm strain (Table 1).

\section{Gene structure of colicin BM plasmids}

Colicin BM plasmids typically encode four colicin genes located within the same $4 \mathrm{~kb}$ region (Fig. 1). These genes are designated $c m i, c m a, c b i$ and $c b a$, and encode the colicin $\mathrm{M}$ immunity, colicin $\mathrm{M}$ activity, colicin B immunity and colicin B activity proteins, respectively (Ölschläger et al., 1984). The colicin $B$ and $M$ gene region was sequenced for a total of $60 \mathrm{E}$. coli strains, including four colicin M strains, 26 colicin MBimm strains and 31 colicin BM strains. All but one of the colicin MBimm strains had an identical colicin gene structure consisting of an intact colicin $\mathrm{M}$ operon and complete $c b i$, together with a $130 \mathrm{bp}$ remnant of $c b a$ (Fig. 1). The one exception was strain TA78, which possessed a considerably larger fragment of $c b a$ $(>1000 \mathrm{bp})$. It is unlikely that TA78 has an intact B activity gene, as no primer binding was observed at the upstream end of the gene (Fig. 1). This atypical colicin MBimm strain has been excluded from many of the subsequent analyses.

A colicin BM plasmid recently sequenced by Johnson et al. (2006a) (pAPEC-O1-ColBM, accession no. DQ381420) was found to have a truncated colicin B activity gene like the colicin MBimm strains examined in this study. The remnant of $c b a$ in pAPEC-O1-ColBM is flanked by an intact conserved hypothetical protein gene of unknown function $(h p)$. PCR screening revealed that $h p$ flanks the partial $c b a$ gene in almost all colicin MBimm strains in our collection (TA78 is the only exception). Nucleotide 
Table 1. Frequency of $E$. coli strains with a colicin BM or MBimm genotype with respect to the host group from which the strain was isolated and the $E$. coli phylogroup membership of the strain (Clermont et al., 2000)

\begin{tabular}{|c|c|c|c|c|}
\hline \multirow[t]{2}{*}{ Host } & \multirow[t]{2}{*}{$\begin{array}{c}\text { E. coli } \\
\text { phylogroup }\end{array}$} & \multirow[t]{2}{*}{ Sample size } & \multicolumn{2}{|c|}{$\begin{array}{c}\text { Strains exhibiting } \\
\text { each colicin genotype } \\
(\%)\end{array}$} \\
\hline & & & $\begin{array}{c}\text { Colicin } \\
\text { BM }\end{array}$ & $\begin{array}{c}\text { Colicin } \\
\text { MBimm }\end{array}$ \\
\hline \multirow[t]{5}{*}{ Animal $^{*}$} & A & 90 & 14.4 & 5.5 \\
\hline & B1 & 270 & 6.7 & 1.5 \\
\hline & B2 & 213 & 15.5 & 3.8 \\
\hline & $\mathrm{D}$ & 112 & 15.2 & 2.7 \\
\hline & Total & 685 & 11.8 & 2.9 \\
\hline \multirow[t]{5}{*}{ Human } & A & 90 & 2.2 & 2.2 \\
\hline & B1 & 51 & 0.0 & 0.0 \\
\hline & B2 & 350 & 0.9 & 1.1 \\
\hline & $\mathrm{D}$ & 128 & 1.6 & 7.8 \\
\hline & Total & 619 & 1.1 & 2.6 \\
\hline
\end{tabular}

*Denotes non-human animals: mammals, birds and reptiles.

sequence data showed that the $h p$ sequence joins the $c b a$ remnant at exactly the same base position in every MBimm strain. Thus, all ColMBimm plasmids possess an identical colicin gene structure. The 31 sequenced colicin BM strains (with an intact $c b a$ ) were also screened for $h p$, and eight of them were positive. The four colicin $M$ strains were negative for $h p$. The SOS box sequence in the $c b a$ promoter region of the colicin $B$ operon (Fig. 1) was present in all sequenced BM strains but was not detected in any MBimm strains.

There were several strains with large nucleotide insertions ( 500-1500 bp) in the colicin B and colicin M activity genes. Strains R981 and B706 contained insertions in $c b a$, and TA445 and M767 contained insertions in cma.

\section{DNA and amino acid sequence variation in colicins $B$ and $M$}

Several previously published colicin B and $M$ sequences were included in the analyses: the colicin region of the plasmid pAPEC-O1-ColBM, and separately published sequences for cmi, cma, cbi and cba (Köck et al., 1987; Ölschläger \& Braun, 1987; Schramm et al., 1987, 1988). Sequence variation statistics and codon-based Z-tests for selection were performed for each colicin gene (Table 2). There was relatively little variation in the colicin genes of the MBimm strains, with only three $c m i$ and $c b i$ alleles and four cma alleles among the 26 strains sequenced (Table 2). Colicin BM strains were much more variable, with between nine $(c m i)$ and $19(c b a)$ different alleles for the four colicin genes. Tests for selection indicated that the $\mathrm{cmi}$, cma and $c b a$ genes are undergoing purifying selection in colicin BM strains, but not in colicin MBimm strains. There was no evidence of selection of the $c b i$ gene in either colicin BM or MBimm strains (Table 2).

\section{Characterization of transconjugant colicin plasmids}

Transconjugants were used to test whether colicin B immunity is functional in strains that have lost B activity. Wild-type strains could not be used due to the high levels of colicin resistance reported in E. coli (Gordon et al., 1998) and observed in this study. Sixteen confirmed transconjugants were obtained: three with ColBM plasmids and 13 with ColMBimm plasmids. The colicin BM and MBimm operons were found to occur on different types of conjugative plasmid backbone (Table 3 ). The majority of the ColMBimm plasmids were finO positive, possessed an F-type traY gene and had IncFII-related replicons. The virulence factors tsh, iroN, sitA, $h l y F$, eitA, iutA and iss were more frequently detected on ColMBimm plasmids than on ColBM plasmids (Table 3). The sizes of the transconjugant plasmids were estimated (Table 3), and ColBM plasmids (average size $85 \mathrm{~kb}$ ) were smaller than ColMBimm
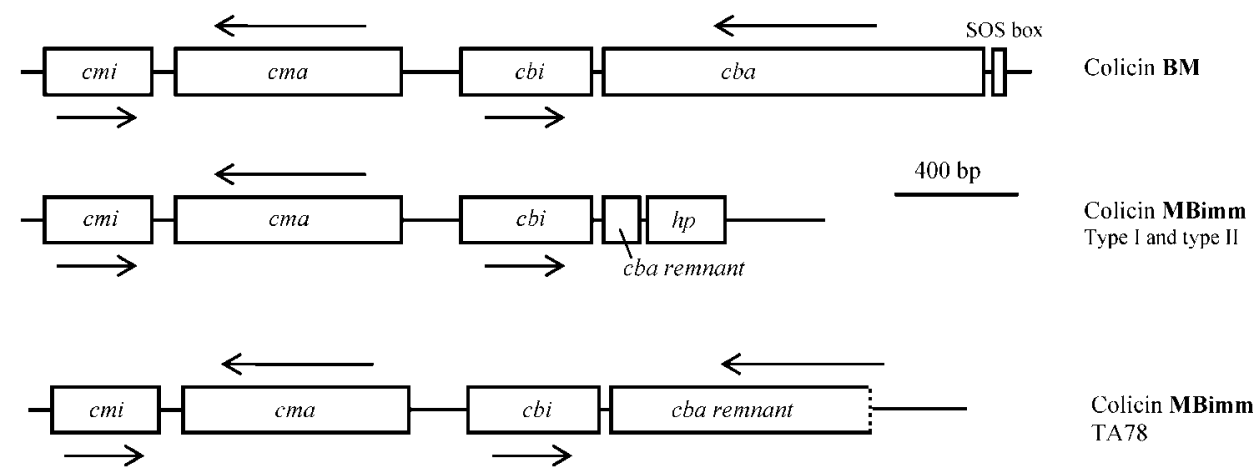

Fig. 1. Colicin gene structure of the colicin $B M$ and colicin MBimm strains sequenced in this study. Arrows indicate direction of transcription. cmi, colicin M immunity; cma, colicin M activity; cbi, colicin B immunity; cba, colicin B activity; $h p$, conserved hypothetical protein gene. 
Table 2. Sequence variation and estimates of selection for each colicin gene with respect to strain colicin genotype (colicin BM or colicin MBimm)

All statistical tests were conducted with MEGA4 (Tamura et al., 2007).

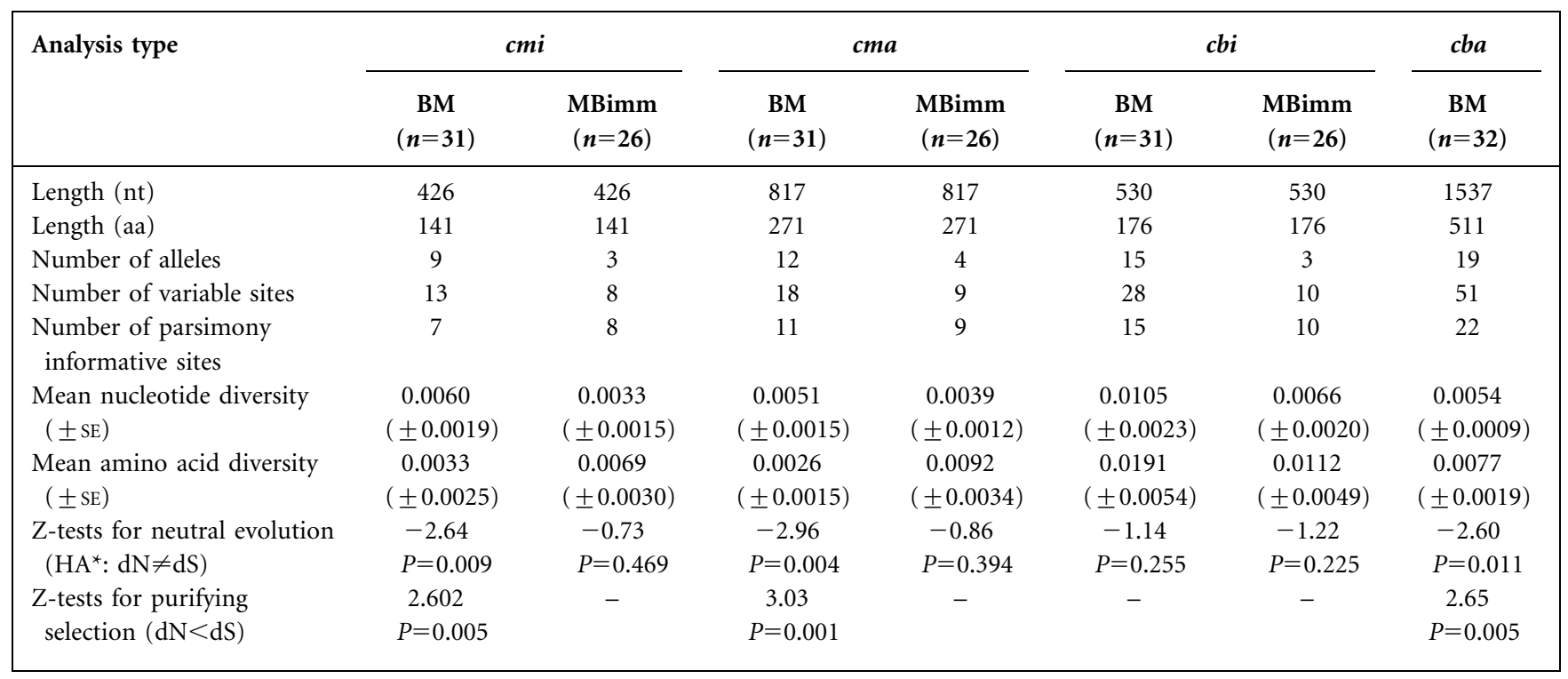

${ }^{\star} \mathrm{HA}$, alternative hypothesis.

plasmids (average size $152 \mathrm{~kb}$ ) (ANOVA: $\mathrm{F}_{(1,16)}=40.96$, $P<0.0001)$.

\section{Phylogenetic analyses of colicin genes}

Maximum-likelihood trees were constructed from the nucleotide sequence data for each of the colicin genes, cmi, cma, cbi and $c b a$ (Fig. 2). The colicin M strains formed a monophyletic group in the $c m i$ and $c m a$ trees, with bootstrap support values of 88 and $100 \%$, respectively. Relatively long branch lengths for the colicin $\mathrm{M}$-alone strains in the cma tree indicated that colicin $\mathrm{M}$ strains are divergent from colicin $\mathrm{BM}$ and MBimm strains. The atypical MBimm strain TA78 was not grouped with the

Table 3. Characteristics of ColBM and ColMBimm transconjugant plasmids (plasmids transferred into host strain BZB1011)

\begin{tabular}{|c|c|c|c|c|c|c|c|c|c|c|c|c|c|}
\hline \multirow{2}{*}{$\begin{array}{l}\text { Donor } \\
\text { strain }\end{array}$} & \multirow{2}{*}{$\begin{array}{l}\text { Col plasmid } \\
\text { type }\end{array}$} & \multicolumn{11}{|c|}{ Plasmid gene } & \multirow{2}{*}{$\begin{array}{l}\text { Plasmid } \\
\text { size }(\mathbf{k b})\end{array}$} \\
\hline & & eitA & sitA & iutA & $t s h$ & iroN & $\operatorname{traT}$ & iss & hlyF & $\operatorname{tra} Y$ & finO & IncFII & \\
\hline TA277 & $\mathrm{BM}$ & - & - & - & - & - & + & - & - & $\mathrm{R} 1$ & + & + & 92 \\
\hline H354 & $\mathrm{BM}$ & - & 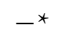 & $-^{\star}$ & - & - & + & - & - & $\mathrm{R} 1$ & + & + & 77 \\
\hline B921 & MBimm & - & + & - & - & + & + & + & + & $\mathrm{F}$ & + & + & 118 \\
\hline H179 & MBimm & + & + & + & + & + & + & + & + & $\mathrm{F}$ & + & + & 154 \\
\hline $\mathrm{H} 270$ & MBimm & + & + & + & + & + & + & + & + & $\mathrm{F}$ & + & - & 145 \\
\hline $\mathrm{H} 279$ & MBimm & + & + & + & + & + & + & + & + & $\mathrm{F}$ & + & - & 154 \\
\hline $\mathrm{H} 457$ & MBimm & + & + & - & - & + & + & + & + & $\mathrm{F}$ & + & + & 162 \\
\hline $\mathrm{H} 463$ & MBimm & + & + & - & - & + & + & + & + & $\mathrm{F}$ & + & + & 162 \\
\hline M1198 & MBimm & - & + & - & - & + & + & + & + & $\mathrm{F}$ & + & + & 118 \\
\hline $\mathrm{R} 432$ & MBimm & + & + & - & - & + & + & + & + & $\mathrm{F}$ & + & + & 156 \\
\hline
\end{tabular}

${ }^{\star}$ These genes were present in the wild-type strain but not in the corresponding colicin plasmid transconjugant. 


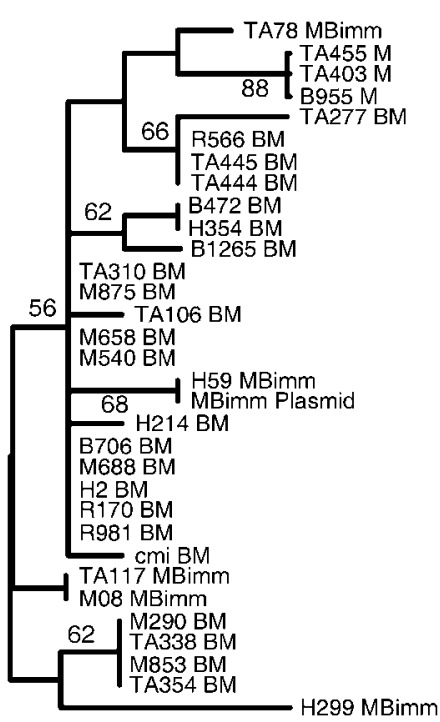

-0.001 substitutions per site

cmi

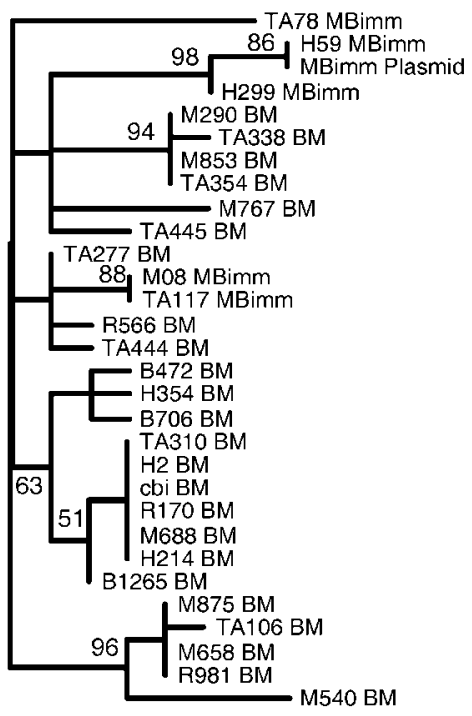

- 0.001 substitutions per site cbi
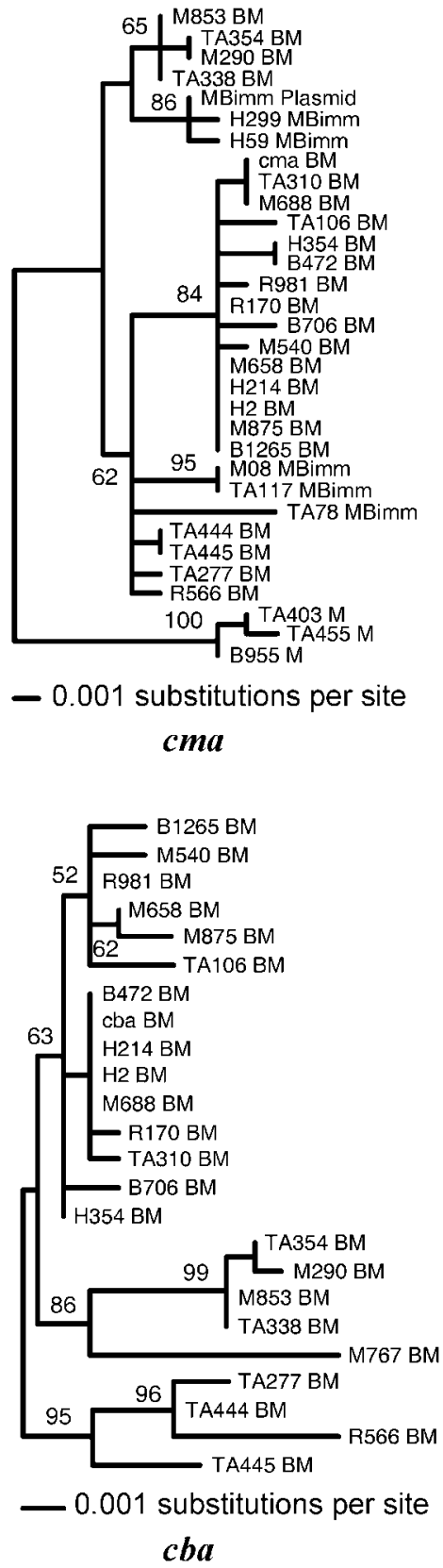

Fig. 2. Maximum-likelihood trees constructed using the nucleotide sequence data for each of the colicin B and M genes. Bootstrap support values are indicated at major nodes. Strains were assigned sequence types based on their entire colicin $B$ and $M$ gene sequence, resulting in 32 sequence types. Only one representative from each sequence type is included. other MBimm strains in any of these trees. The remaining MBimm strains formed at least two separate clades in each of the cmi, cma and cbi trees.

\section{Characterization and evolution of colicin BM plasmids}

A maximum-likelihood tree was constructed from the largest fragment that could be aligned for all colicin BM and colicin MBimm nucleotide sequences, a 2289 bp fragment including the cmi, cma and $c b i$ genes (Fig. 3). The resulting tree shows high bootstrap support at all major nodes, except for one very short node at the edge of the tree. The colicin MBimm operons form two separate clades in this tree, and their plasmids have been designated type I and type II ColMBimm plasmids (Fig. 3). The type I group contains 20 strains and three sequence types (STs), and the type II group contains six strains and two STs. The type I ColMBimm strains form a monophyletic group (with $100 \%$ bootstrap support) with a group of seven colicin BM strains (M853, M854, etc.).

As observed for the transconjugant strains, ColBM and ColMBimm plasmids differ in more respects than simply by their colicin B and M gene structure (Fig. 3). Among the plasmids whose colicin genes were sequenced (Fig. 3), ColBM plasmids were also found to be significantly smaller than ColMBimm plasmids (ANOVA: $\mathrm{F}_{(1,34)}=15.70$, 

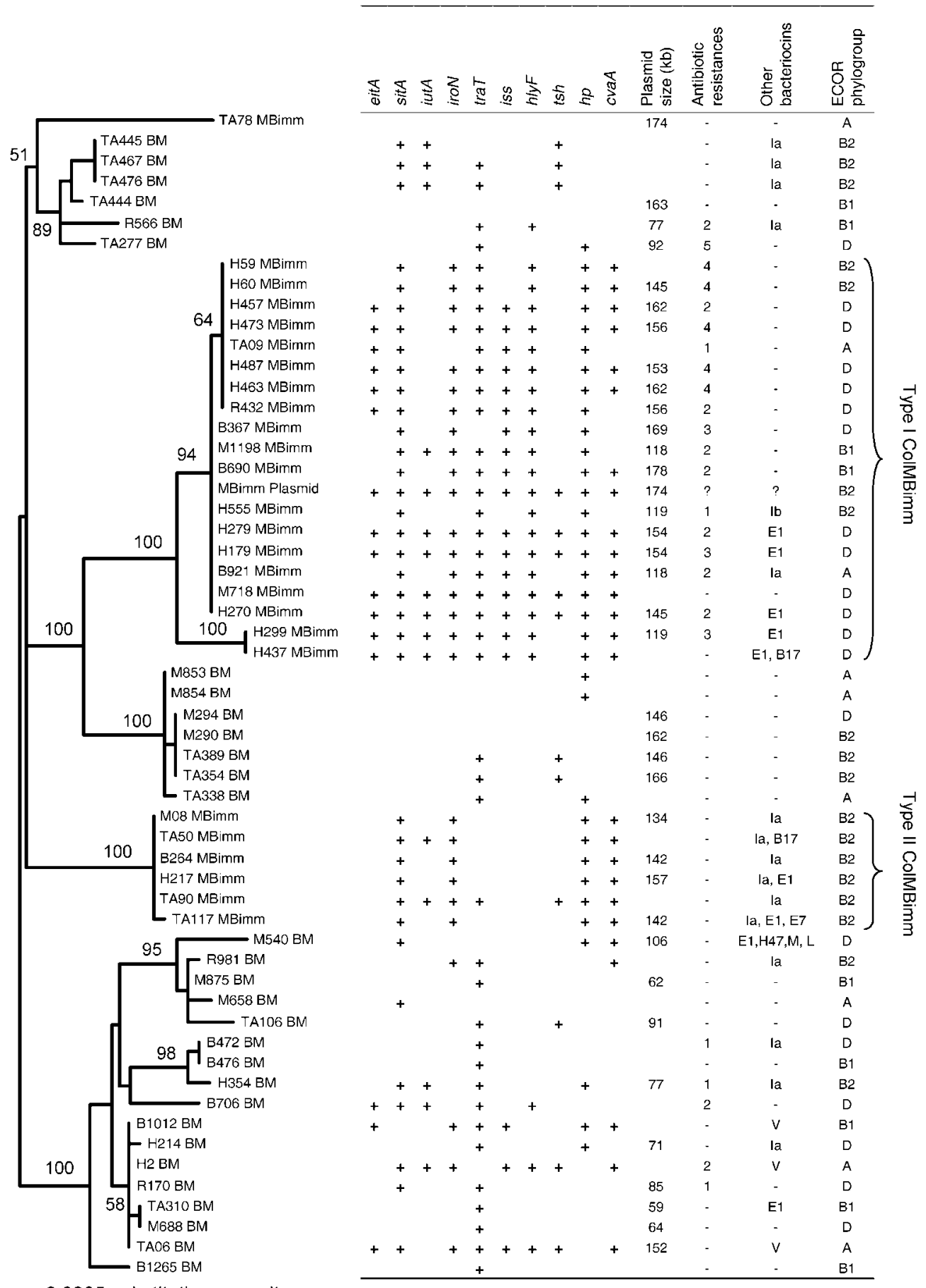

-0.0005 substitutions per site

Fig. 3. Maximum-likelihood tree constructed using the cmi-cma-cbi nucleotide sequence of colicin BM and MBimm strains. Strains are labelled with a letter prefix indicating host group: $\mathrm{H}$, human; M/TA, mammal (non-human); R, reptile; $\mathrm{B}$, bird. Bootstrap support values are indicated at major nodes. Possession of various plasmid-encoded traits is indicated by + . Colicin plasmid sizes are included for strains that contained only one plasmid $>30 \mathrm{~kb}$ or for which a Col plasmid transconjugant was obtained. Also shown for each strain are the other known bacteriocins present (colicins la, lb, E1, E7 and L, and microcins V, $\mathrm{B} 17, \mathrm{M}$ and $\mathrm{H} 47$ ) and the $E$. coli phylogroup (Clermont et al., 2000). Strains were screened for resistance to seven antibiotics (streptomycin, tetracycline, chloramphenicol, trimethoprim, sulfamethoxazole trimethoprim, ampicillin and kanamycin) and the number of resistances for each strain is indicated. Strains that were susceptible to all eight antibiotics are marked with '-'. 
$P=0.0004$; mean \pm SE plasmid sizes $(\mathrm{kb}): B M=107 \pm 8$, MBimm $=148 \pm 7)$. PCR screening of wild-type strains for putatively plasmid-borne virulence traits (eitA, sitA, iutA, iroN, traT, iss, $h l y F$ and tsh) further emphasized the differences between ColBM and ColMBimm plasmids (Fig. $3)$. In addition to the hypothetical protein gene $(h p)$ that abuts the remnant of $c b a$, all sequenced strains were PCRscreened for the presence of $c v a A$, which is located about $2.5 \mathrm{~kb}$ from the $c b a$ remnant in the fully sequenced plasmid pAPEC-O1-ColBM. All ColMBimm plasmids (but only some ColBM plasmids) encode sit $A$ and $h p$, and most ColMBimm plasmids encode iroN and $c v a A$. The microcin $\mathrm{V}$ export gene cvaA was present in all but five MBimm strains and absent from all but five BM strains (Fig. 3).

The plasmid genomes of the two types of ColMBimm plasmids also differ. Unlike type I ColMBimm plasmids, type II plasmids do not encode eitA, iss or $h l y F$, but all type II MBimm strains encode colicin Ia and belong to phylogroup B2 (Fig. 3).

The same differences in the plasmid genomes of colicin BM and MBimm strains were observed when the entire collection of 124 strains representing either BM or MBimm strains were screened for the presence of the plasmid-determined traits. Strains encoding only the colicin $\mathrm{M}$ operon were negative for all of these traits, and the E. coli transport system element ets $A$ was detected in only a single colicin BM strain. Except for tsh and traT, all of the putative plasmid-borne traits were significantly more frequent in colicin MBimm strains than in colicin BM strains (Table 4).

\section{Is colicin B immunity functional in ColMBimm plasmids?}

The observation that the B immunity gene in ColMBimm plasmids is completely intact suggested that it may be functional. ColMBimm transconjugants (Table 3) were treated with extracts from three different colicin BM strains to determine whether this was the case. Cells of the ColBM transconjugants were not killed, but all 13 ColMBimm transconjugants were killed by the BM extracts, indicating that their B immunity genes are non-functional. Examination of amino acid variation in $c b i$ showed fixed amino acid differences between the colicin MBimm strains and the BM strains. The type I ColMBimm plasmids possessed two amino acid differences in the B immunity gene at positions 65 and 108, while the type II ColMBimm plasmids possessed a single fixed amino acid difference at position 175 (data not shown). In a strain with a functional $\mathrm{B}$ activity gene the $\mathrm{B}$ immunity gene is under constant pressure to maintain its amino acid sequence. A change in the immunity protein may decrease its binding affinity for the colicin B protein, and if a colicin B cell is unable to inactivate its own colicin, it will quickly die. In colicin MBimm strains, the selective pressure on colicin B immunity has been removed by the loss of the B activity gene. This has allowed the accumulation of mutations and amino acid differences in $c b i$, which may have resulted in the loss of gene function.

\section{Is colicin M produced in strains without colicin B activity?}

The production of most colicins is SOS-induced, and in colicin BM strains, the production of both colicins appears to be regulated at the same SOS box located upstream of cba (Gillor et al., 2008b; Köck et al., 1987; Ölschläger et al., 1984). This SOS box is absent in MBimm strains; thus, it is possible that colicin $\mathrm{M}$ production can no longer occur in these strains. Unlike other colicins, colicin $\mathrm{M}$ cannot be induced by the DNA mutagen mitomycin C (Braun et al., 1974); therefore, an alternative method for detecting colicin $\mathrm{M}$ production was required. The colicin MBimm strains were tested for a killing phenotype by using an indicator lawn of the sensitive laboratory strain BZB1011 on Luria agar plates containing tetracycline. Seven out of nine tetracycline-resistant colicin MBimm strains showed a killing zone on the BZB1011 lawn, indicating colicin production. Similar results were achieved with the ColMBimm transconjugant strains corresponding to these wild-type strains. It is not known why a killing phenotype can be observed in these strains only when tetracycline is added to the Luria agar plates (no killing phenotypes were observed when another bacteriostatic antibiotic, trimethoprim, was used). Of the seven colicin MBimm strains with a positive killing phenotype, only one had screened positive

Table 4. Frequency of plasmid-encoded virulence genes in colicin BM and MBimm E. coli isolates with respect to Col plasmid type

\begin{tabular}{|c|c|c|c|c|}
\hline Gene & Encoded trait & Colicin BM $(n=88)$ & Colicin MBimm $(n=36)$ & $P>\chi^{2 x}$ \\
\hline eitA & Putative iron transport system element & $8 \%$ & $50 \%$ & $<0.0001$ \\
\hline sitA & Putative iron transport system element & $41 \%$ & $100 \%$ & $<0.0001$ \\
\hline iutA & Ferric aerobactin receptor & $17 \%$ & $36 \%$ & 0.0251 \\
\hline iroN & Catecholate siderophore receptor & $10 \%$ & $83 \%$ & $<0.0001$ \\
\hline $\operatorname{traT}$ & Complement resistance and surface exclusion & $65 \%$ & $81 \%$ & 0.0754 \\
\hline iss & Increased serum survival & $5 \%$ & $67 \%$ & $<0.0001$ \\
\hline$h l y F$ & Putative haemolysin & $7 \%$ & $75 \%$ & $<0.0001$ \\
\hline$t s h$ & Temperature-sensitive haemagglutinin & $32 \%$ & $22 \%$ & 0.2774 \\
\hline
\end{tabular}

${ }^{\star}$ Likelihood ratio test of trait frequency: colicin BM versus colicin MBimm. 
for another bacteriocin. This suggests that colicin $M$ production is still occurring in the strains that have lost colicin B activity. Another possibility is that colicin $\mathrm{M}$ is constitutively produced at low levels in strains without colicin B and that this low level of colicin production is sufficient to result in a killing phenotype. It is unlikely that the presence of another unknown bacteriocin in these transconjugant ColMBimm plasmids strains is responsible for the killing phenotypes observed. No other bacteriocinlike sequence was detected in the fully sequenced colicin plasmid pAPEC-O1-ColBM or in another fully sequenced type I ColMBimm plasmid, pSMS35-130 (GenBank accession no. CP000971), and these sequenced plasmids are highly similar to all type I ColMBimm plasmids investigated in this study.

\section{DISCUSSION}

Almost all of the colicin B or M plasmids examined in this study encoded both colicins (ColBM plasmids) or once encoded both colicins (ColMBimm plasmids). Phylogenetic analyses on the colicin genes (Fig. 2) indicated that in the four plasmids encoding only the colicin $\mathrm{M}$ operon, $\mathrm{cmi}$ and cma are highly divergent compared with these genes in ColBM and ColMBimm plasmids. This suggests that in ColM plasmids the $\mathrm{M}$ operon has never been associated with colicin B genes. Among 1304 isolates examined in this study, no example of a strain with a colicin B operon in the absence of colicin M was observed, although Johnson et al. (2006a) provided evidence that such strains do exist. However, without nucleotide sequence data for the B operon in colicin Balone strains, it is not possible to determine whether their colicin plasmids once encoded both colicin B and colicin M or whether they represent cases where the colicin $\mathrm{M}$ operon has never been present. Few data are available with which to infer how ColBM plasmids evolved, but the observed nucleotide sequence diversity suggests that they have existed in E. coli for a significant time period. The fact that they are among the most abundant colicins in E. coli isolated from non-human vertebrates (Gordon et al., 2007) also indicates their long association with these species.

The results of this study show that colicin BM plasmids with a truncated B activity gene have evolved on at least three separate occasions. The first of these occasions is represented by E. coli strain TA78, which contains approximately 1000 bases of the colicin B activity gene but seems to lack the upstream end (Figs 1 and 3). The other two occasions are represented by the type I and type II ColMBimm plasmids. Although the colicin gene structure of these two plasmid types is identical (Fig. 1), they clearly form two distinct clades with high bootstrap support (Fig. 3). The phylogenetic analysis also indicates that the colicin $\mathrm{M}$ operon and $\mathrm{B}$ immunity gene found on type I and type II MBimm plasmids had two different colicin BM ancestors. Furthermore, the virulence gene profiles of type I and type II MBimm plasmids are quite distinct.
The evolution of the type I and II MBimm plasmids appears to have involved the acquisition of genes normally found on ColV plasmids. Many plasmids that encode multiple bacteriocins encode microcin V. Indeed, microcin $\mathrm{V}$ has been found together with a number of colicins known to be encoded on conjugative plasmids in E. coli: Ia, $\mathrm{Ib}, \mathrm{B}$ and $\mathrm{M}$ (Gordon et al., 2007). In a recent study, Johnson et al. (2006a) compared the genomes of the microcin $\mathrm{V}$ plasmid pAPEC-O2-ColV and the colicin BM plasmid pAPEC-O1-ColBM. In fact, pAPEC-O1-ColBM actually represents a type I ColMBimm plasmid and was found to contain a putative virulence cluster (eit $A B C D$, sit $A B C D$, aerobactin, salmochelin, iss, tsh and ets $A B C$ ) normally associated with ColV plasmids, as well as remnants of the microcin $\mathrm{V}$ operon. In this study, microcin $\mathrm{V}$ gene remnants $(c v a A)$ and associated virulence genes were detected on most of the type I and II ColMBimm plasmids as well as on two colicin BM plasmids (Fig. 3). There was also a case in which an apparently intact microcin $\mathrm{V}$ gene cluster was present on a ColBM plasmid together with most of the ColV plasmid-associated virulence genes (strain TA06, Fig. 3).

When microcin $\mathrm{V}$ and colicin Ia co-occur on the same plasmid, both bacteriocin operons are intact and two virulence factors normally associated with ColV plasmids, iss and iroBCDEN, are always present (Jeziorowski \& Gordon, 2007). Those authors argue that evidence presented in their study is consistent with the hypothesis that ColIaV plasmids evolved as a consequence of the movement of microcin $\mathrm{V}$ and associated virulence factors onto traT-positive ColIa plasmids. Yet Johnson et al. (2006a) speculate that pAPEC-O1-ColBM may have evolved from an ancestral ColV plasmid. So have ColMBimm plasmids evolved as a consequence of the movement of the colicin $\mathrm{B}$ and $\mathrm{M}$ operons onto a ColV plasmid, or did the microcin $\mathrm{V}$ operon together with at least a portion of the ColV plasmid virulence gene cluster move onto a plasmid encoding colicins B and $\mathrm{M}$ ? We argue that the latter hypothesis is the more likely, although the evidence is less compelling than in the colicin Ia and microcin $\mathrm{V}$ association.

The evolution of ColMBimm plasmids has resulted in the loss of colicin B and microcin V activity and immunity. Thus, if the evolution of these plasmids has involved the movement of only the colicin B and $\mathrm{M}$ operons, then any selective advantage gained by such newly evolved strains would have to be a consequence of a ColV plasmid acquiring colicin M. However, it seems unlikely that the acquisition of colicin $\mathrm{M}$ confers a significant advantage to colicin MBimm strains. In vitro and in vivo empirical studies have demonstrated that colicins have the potential to mediate competitive interactions among bacterial strains (Kirkup \& Riley, 2004; Riley \& Gordon, 1999). However, most natural isolates of E. coli are resistant to most colicins (Gordon et al., 1998; Riley \& Gordon, 1992). Colicin M is produced at very low levels in MBimm strains, and the ability of a colicin-producing strain to invade a sensitive 
cell population has been shown to increase as the amount of colicin produced increases (Gordon \& Riley, 1999). Furthermore, analysis of the sequence data from this study shows that the colicin $\mathrm{M}$ genes are under purifying selection in ColBM plasmids but not in ColMBimm plasmids (Table 2), suggesting that selection is not acting to maintain colicin $\mathrm{M}$ in ColMBimm plasmids.

In contrast, a significant fitness gain may result from the acquisition of ColV-plasmid-encoded traits. Although microcin $\mathrm{V}$ itself has not been implicated as a virulence factor in avian extra-intestinal infection, other traits present on ColV plasmids, such as iss, may contribute to virulence (Skyberg et al., 2006, 2008). In addition, iron is the major limiting factor for bacteria attempting to colonize extra-intestinal body sites (Ratledge \& Dover, 2000), and many of the traits in the ColV plasmid virulence gene cluster are involved in iron acquisition. Thus, the gain of the traits in the ColV virulence gene cluster as a consequence of the movement of the ColV genes onto a ColBM plasmid is likely to represent a greater gain in fitness than the acquisition of colicin $\mathrm{M}$ production by a ColV plasmid. This supports the hypothesis that ColMBimm plasmids evolved as a consequence of the microcin $\mathrm{V}$ operon and associated virulence genes moving onto a plasmid encoding colicins B and $\mathrm{M}$.

The evolution of these co-associations involving ColVassociated traits appears to be occurring largely among isolates harboured by humans and domesticated animals. Among Australian E. coli isolates, ColIa or ColBM plasmids are more frequently observed in isolates from native vertebrates than in isolates from humans (Gordon et al., 2007; Jeziorowski \& Gordon, 2007). In contrast, strains harbouring the microcin $\mathrm{V}$ operon are far more frequently recovered from humans than from animals (Gordon et al., 2007). However, Johnson et al. (2006b) have reported that ColV plasmids are very common among avian pathogenic isolates of E. coli. Thus, ColV-plasmid-associated genes may be exploiting a variety of 'native' E. coli plasmids that normally encode colicins, enabling ColV plasmid genes to spread among different E. coli lineages. Although it is well known that antibiotic use has resulted in the creation and dissemination of a diversity of ' $R$ ' plasmids, the results of this study and others suggest that virulence can also be a significant force in plasmid evolution.

\section{ACKNOWLEDGEMENTS}

This study was supported by an Australian Research Council Discovery Project grant.

\section{REFERENCES}

Boyd, E. F., Hill, C. W., Rich, S. M. \& Hartl, D. L. (1996). Mosaic structure of plasmids from natural populations of Escherichia coli. Genetics 143, 1091-1100.
Braun, V. (1995). Energy-coupled transport and signal-transduction through the Gram-negative outer-membrane via TonB-ExbB-ExbDdependent receptor proteins. FEMS Microbiol Rev 16, 295-307.

Braun, V., Schaller, K. \& Wabl, M. R. (1974). Isolation, characterization and action of colicin-M. Antimicrob Agents Chemother 5, 520533.

Braun, V., Patzer, S. I. \& Hantke, K. (2002). Ton-dependent colicins and microcins: modular design and evolution. Biochimie 84, 365-380.

Clermont, O., Bonacorsi, S. \& Bingen, E. (2000). Rapid and simple determination of the Escherichia coli phylogenetic group. Appl Environ Microbiol 66, 4555-4558.

Czaran, T. L., Hoekstra, R. F. \& Pagie, L. (2002). Chemical warfare between microbes promotes biodiversity. Proc Natl Acad Sci U S A 99, 786-790.

de Souza, M. L., Wackett, L. P. \& Sadowsky, M. J. (1998). The atzABC genes encoding atrazine catabolism are located on a self-transmissible plasmid in Pseudomonas sp. strain ADP. Appl Environ Microbiol 64, 2323-2326.

Gillor, O., Kirkup, B. C. \& Riley, M. A. (2004). Colicins and microcins: the next generation antimicrobials. In Advances in Applied Microbiology, vol. 54, pp. 129-146. Edited by A. I. Laskin, J. W. Bennett \& G. M. Gadd. Amsterdam: Elsevier.

Gillor, O., Etzion, A. \& Riley, M. A. (2008a). The dual role of bacteriocins as anti- and probiotics. Appl Microbiol Biotechnol 81, 591-606.

Gillor, O., Vriezen, J. A. C. \& Riley, M. A. (2008b). The role of SOS boxes in enteric bacteriocin regulation. Microbiology 154, 1783-1792.

Gordon, D. M. \& Cowling, A. (2003). The distribution and genetic structure of Escherichia coli in Australian vertebrates: host and geographic effects. Microbiology 149, 3575-3586.

Gordon, D. M. \& O'Brien, C. L. (2006). Bacteriocin diversity and the frequency of multiple bacteriocin production in Escherichia coli. Microbiology 152, 3239-3244.

Gordon, D. M. \& Riley, M. A. (1999). A theoretical and empirical investigation of the invasion dynamics of colicinogeny. Microbiology 145, 655-661.

Gordon, D. M., Riley, M. A. \& Pinou, T. (1998). Temporal changes in the frequency of colicinogeny in Escherichia coli from house mice. Microbiology 144, 2233-2240.

Gordon, D. M., Stern, S. E. \& Collignon, P. J. (2005). Influence of the age and sex of human hosts on the distribution of Escherichia coli ECOR groups and virulence traits. Microbiology 151, 15-23.

Gordon, D. M., Oliver, E. \& Littlefield-Wyer, J. (2007). The diversity of bacteriocins in Gram-negative bacteria. In Bacteriocins: Ecology and Evolution, pp. 5-18. Edited by M. A. Riley \& M. A. Chavan. New York: Springer.

Harkness, R. E. \& Braun, V. (1989a). Inhibition of lipopolysaccharide O-antigen synthesis by colicin-M. J Biol Chem 264, 14716-14722.

Harkness, R. E. \& Braun, V. (1989b). Colicin-M inhibits peptidoglycan biosynthesis by interfering with lipid carrier recycling. J Biol Chem 264, 6177-6182.

Harkness, R. E. \& Ölschläger, T. (1991). The biology of colicin-M. FEMS Microbiol Rev 8, 27-41.

Jeziorowski, A. \& Gordon, D. M. (2007). Evolution of microcin V and colicin Ia plasmids in Escherichia coli. J Bacteriol 189, 7045-7052.

Johnson, T. J., Johnson, S. J. \& Nolan, L. K. (2006a). Complete DNA sequence of a ColBM plasmid from avian pathogenic Escherichia coli suggests that it evolved from closely related ColV virulence plasmids. J Bacteriol 188, 5975-5983.

Johnson, T. J., Siek, K. E., Johnson, S. J. \& Nolan, L. K. (2006b). DNA sequence of a ColV plasmid and prevalence of selected 
plasmid-encoded virulence genes among avian Escherichia coli strains. J Bacteriol 188, 745-758.

Kirkup, B. C. \& Riley, M. A. (2004). Antibiotic-mediated antagonism leads to a bacterial game of rock-paper-scissors in vivo. Nature $\mathbf{4 2 8}$, $412-414$

Köck, J., Ölschläger, T., Kamp, R. M. \& Braun, V. (1987). Primary structure of colicin-M, an inhibitor of murein biosynthesis. J Bacteriol 169, 3358-3361.

Lu, F. M. \& Chak, K. F. (1996). Two overlapping SOS-boxes in ColE operons are responsible for the viability of cells harboring the $\mathrm{Col}$ plasmid. Mol Gen Genet 251, 407-411.

Ölschläger, T. \& Braun, V. (1987). Sequence, expression and localization of the immunity protein for colicin-M. J Bacteriol 169, 4765-4769.

Ölschläger, T., Schramm, E. \& Braun, V. (1984). Cloning and expression of the activity and immunity genes of colicin-B and colicin-M on ColBM plasmids. Mol Gen Genet 196, 482-487.

Osborn, A. M., Tatley, F. M. D., Steyn, L. M., Pickup, R. W. \& Saunders, J. R. (2000). Mosaic plasmids and mosaic replicons: evolutionary lessons from the analysis of genetic diversity in IncFIIrelated replicons. Microbiology 146, 2267-2275.

Posada, D. \& Crandall, K. A. (1998). modeltest: testing the model of DNA substitution. Bioinformatics 14, 817-818.

Pressler, U., Braun, V., Wittmannliebold, B. \& Benz, R. (1986). Structural and functional properties of colicin-B. J Biol Chem 261, 2654-2659.

Pugsley, A. P. (1985). Escherichia coli-K12 strains for use in the identification and characterization of colicins. J Gen Microbiol 131, 369-376.

Pugsley, A. P. \& Oudega, B. (1987). Methods of studying colicins and their plasmids. In Plasmids: a Practical Approach, pp. 105-161. Edited by K. G. Hardy. Oxford: IRL Press.

Ratledge, C. \& Dover, L. G. (2000). Iron metabolism in pathogenic bacteria. Annu Rev Microbiol 54, 881-941.

Riley, M. A. \& Gordon, D. M. (1992). A survey of Col plasmids in natural isolates of Escherichia coli and an investigation into the stability of Col-plasmid lineages. J Gen Microbiol 138, 1345-1352.
Riley, M. A. \& Gordon, D. M. (1999). The ecological role of bacteriocins in bacterial competition. Trends Microbiol 7, 129-133.

Riley, M. A. \& Wertz, J. E. (2002). Bacteriocin diversity: ecological and evolutionary perspectives. Biochimie 84, 357-364.

Riley, M. A., Goldstone, C. M., Wertz, J. E. \& Gordon, D. (2003). A phylogenetic approach to assessing the targets of microbial warfare. J Evol Biol 16, 690-697.

Rodriguez-Siek, K. E., Giddings, C. W., Doetkott, C., Johnson, T. J. \& Nolan, L. K. (2005). Characterizing the APEC pathotype. Vet Res 36, 241-256.

Sasarman, A., Massie, B., Zollinger, M., Gagnetellier, H., Shareck, F., Garzon, S. \& Morisset, R. (1980). Naturally-occurring RcolBM plasmids belonging to the IncfIII incompatibility group. J Gen Microbiol 119, 475-483.

Schaller, K., Holtje, J. V. \& Braun, V. (1982). Colicin-M is an inhibitor of murein biosynthesis. J Bacteriol 152, 994-1000.

Schramm, E., Mende, J., Braun, V. \& Kamp, R. M. (1987). Nucleotidesequence of the colicin-B activity gene $c b a$ : consensus pentapeptide among TonB-dependent colicins and receptors. J Bacteriol 169, 33503357.

Schramm, E., Ölschläger, T., Troger, W. \& Braun, V. (1988). Sequence expression and localization of the immunity protein for colicin-B. Mol Gen Genet 211, 176-182.

Skyberg, J. A., Johnson, T. J., Johnson, J. R., Clabots, C., Logue, C. A. \& Nolan, L. K. (2006). Acquisition of avian pathogenic Escherichia coli plasmids by a commensal $E$. coli isolate enhances its abilities to kill chicken embryos, grow in human urine and colonize the murine kidney. Infect Immun 74, 6287-6292.

Skyberg, J. A., Johnson, T. J. \& Nolan, L. K. (2008). Mutational and transcriptional analyses of an avian pathogenic Escherichia coli CoIV plasmid. BMC Microbiol 8, 24.

Swofford, D. L. (1993). PAUP - a computer program for phylogenetic inference using maximum parsimony. J Gen Physiol 102, A9-A9.

Tamura, K., Dudley, J., Nei, M. \& Kumar, S. (2007). MEGA4: molecular evolutionary genetics analysis (MEGA) software version 4.0. Mol Biol Evol 24, 1596-1599.

Edited by: L. S. Frost 